\title{
Poéticas caribeñas de la niñería perversa: infancia en textos de Junot Díaz, Severo Sarduy y Rita Indiana Hernández
}

\section{Caribbean Poetics of Childish Perversity: Childhood in Texts by Junot Díaz, Severo Sarduy and Rita Indiana Hernández}

\author{
Fernanda Bustamante Escalona \\ Universitat Autònoma de Barcelona \\ fernandabustamante@gmail.com
}

\section{Resumen:}

El análisis se centra en textos de Junot Díaz, Severo Sarduy y Rita Indiana Hernández, en los que el desconocimiento, la ingenuidad y curiosidad infantil permiten un actuar y un decir liberados de estereotipos, eufemismos y de la dicotomía bien/mal, generando una narración que -bajo un discurso fantasioso y fantasmagórico, inocente y perverso-, presenta un Caribe que ya no es un paraíso perdido, y niños que no son espacio de pureza. Es decir, estos relatos presentan la realidad caribeña bajo una estética de la niñería: lo caribeño se narra desde el juego y desde los niños, y su realidad se narra como un hecho de poca importancia, en una discursividad que no acusa a nadie pero a la vez acusa a todos.

Palabras clave: literatura del Caribe, infancia, perversidad, monstruosidad, espectáculo.

\begin{abstract}
:
The analysis focuses on writings by Junot Diaz, Severo Sarduy and Rita Indiana Hernández in which the child innocence, ignorance and curiosity produces behaviours that are far from stereotypes, euphemisms and the dichotomy good / evil. Under a phantasmagorical and fantastic discourse -which is simultaneously innocent and perverse- these texts present a Caribbean that is neither a lost paradise nor is infancy a state of purity.

There for these texts approach Caribbean reality under a childish aesthetic: The Caribbean is narrated like childsplay, by children who speak of reality as an unimportant fact; in a discourse that is not accusing anyone yet accuses everyone.
\end{abstract}

Keywords: Caribbean Literature, Childhood, Perversity, Monstrosity, Spectacle. 
Una lectura que vincule el Caribe literario y la infancia implica no solo identificar las voces infantiles que representan el Caribe sino también los discursos que lo han delineado como un infante. Roberto Fernández Retamar señala que la imagen del hombre americano fue construida a partir de una "versión degradada que ofrece el colonizador" (25), en la que resaltaron atribuciones como bárbaro y primitivo en cuanto a su desarrollo, y salvaje por su antropofagia. En consecuencia, y como propio de la retórica moderna, "la conexión explícita de las etapas del desarrollo psicológico del individuo con los periodos del desarrollo sociocultural de la humanidad" (Cabo 95) equiparó a los pueblos colonizados con la niñez y a los desarrollados con la adultez $z^{1}$. De esta forma, tomo el concepto-metáfora del Calibán como entrada para esta lectura, la cual tiene como base la idea de que el Caribe es monstruo en cuanto a su disposición a la crueldad, propia del caníbal; así como el Caribe es infante por su condición subalterna de colonizado.

Presentaré una lectura de tres textos narrativos caribeños en los que la representación de este espacio, realizada a partir de voces infantiles, se vuelve una instancia de politización y de exploración estética e identitaria (y acaso ética también). En el cuento "Ysrael" (1996) del dominicano-americano Junot Díaz, la novela Cocuyo (1990) del cubano Severo Sarduy, y la novela Papi (2005) de la dominicana Rita Indiana Hernández, la violencia y la exclusión social, identificadas por Antonio Benítez Rojo en La isla que se repite como rasgos medulares que le subyacen al Caribe (256), cobran protagonismo.

Los relatos dan cuenta de la corrupción y pobreza urbana, de la inmigración como un fenómeno de fragmentación social y dislocación; del racismo y la homofobia como imposiciones identitarias coercitivas; y de la alienación de los sujetos ante el consumo y el mercado. Y es precisamente en la figura del infante y sus conductas donde esta violencia se inscribe y materializa. Los niños protagonistas se presentan como receptáculos de una conflictiva estructura social y como agentes de agresividad, dando cuenta, al seguir a Andrea Jeftanovic, sobre cómo “estos sujetos 'menores' sirven de metáfora [...] de la inherente pulsión de dominación y aniquilación” (11). Frente a tal punto, en esta lectura, que implica repensar la figura de la niñez será esclarecedor el modelo de textos postinfantiles presentado por Eloy Fernández Porta, el cual es entendido como "un modelo de relato [...] que obtiene su efecto estético de la problematización de las ideas culturales sobre el niño" (Relatos 316).

Por tanto, la reflexión gira en torno a cómo estos textos se apropian o se aproximan a la realidad caribeña a partir de lo que denominaré una poética de la niñería: lo caribeño se relata desde los niños y su realidad se narra como un hecho de poca importancia, todo ello bajo una discursividad que no acusa a nadie pero a la vez acusa a todos.

1 Fernando Cabo en Infancia y modernidad literaria desarrolla la idea de cómo las diferencias temporales se espacializan señalando que: 'En este marco los 'primitivos', los 'salvajes', serían testimonios vivientes de estados anteriores al nuestro; y, en cierto modo, su situación, equivalente a la de la niñez. Se propugna así, en suma, la idea de la contemporaneidad de edades y estadios temporales diferentes (de lo primitivo y lo desarrollado, de lo infantil y lo adulto, de lo simple y lo complejo), al menos en cuanto a modelos culturales" (Cabo 92). 


\section{"Ysrael” de Junot Díaz: el morbo infantil}

Como es propio de las obras de Díaz, no solo se nos inserta en relatos donde la diáspora es el eje organizador, sino que se da paso al cuestionamiento de las tendencias homogeneizantes y esencialistas del imaginario social y cultural dominicano y, de esta forma, se reprimen los impulsos unificadores y exotistas. La "nacionalidad ficticia" como la llama Silvio Torres Saillant (2003) -vinculada a la noción de "comunidades imaginadas" de Benedict Anderson- de la que se ha servido el discurso oficial y que demarca la dominicanidad en un sujeto blanco, de cultura europea, religión católica y heterosexual, en el relato pierde toda legitimidad.

En el cuento "Ysrael"2 los protagonistas son niños mulatos de situación social baja, tal como lo señala el propio autor, son sujetos que han "tenido una infancia tercermundista" (Díaz 34) y que están insertos en un entorno familiar fracturado debido a la inmigración de su padre a los Estados Unidos.

En el texto las dinámicas infantiles son representadas de manera sencilla y cotidiana. En cierta medida continúan obedeciendo a un patrón regular de lo que se concibe como propio de la niñez: Yúnior de 8 años nos narra las andanzas de él y su hermano mayor, Rafa, de 12 años, durante los veranos que se iban a un pueblo cerca de Ocoa. Cazar hurones, molestar a los gallos, estafar a los cobradores de las guaguas, así como la búsqueda de las chicas y los consiguientes encuentros sexuales, vienen a ser parte de las actividades/juegos que ambos realizan para "estar ocupados" (Díaz 12), para distraerse y no aburrirse.

La situación de subordinación de Yúnior, el menor ${ }^{3}$, es acentuada por la ausencia del padre, con lo que Rafa adquiere mayor autoridad, ya no solo por la diferencia de edad sino también porque pasa a ser un referente paterno y masculino, en el que se inscribe el discurso hegemónico. Rafa tiene el control sobre su hermano quien no solo es más ingenuo sino más influenciable. Es él quien lo hace callar y le reprime sus llantos y reacciones cobardes afeminadas: "Si no paras de llorar, te dejo aquí. [...] ¿Terminaste? [...] ¿Vas a ser un pendejo toda la vida? [...] Tienes que ser más duro. Siempre llorando" (Díaz 21). También es Rafa quien, en la clásica maldad del hermano mayor de decirle al menor que es un huérfano encontrado en la calle, reproduce el discurso xenófobo identitario dominicano fundado en la retórica colonial y consolidado durante el trujillato: "me echaba en cara los mismos quinientos reproches de siempre. La mayoría eran alusiones al color de mi piel, a mi pelo o al grosor de mis labios. Es haitiano, les decía a sus compadres. Eh, señor haitiano, mami te encontró en la frontera y te recogió porque le diste lástima” (Díaz 13).

2 El cuento forma parte del libro Drown (1996), el cual ha sido traducido al castellano como Negocios, Los Boys. Para efectos del análisis usaré la edición al castellano de Mondadori (2009), Los Boys.

3 Resulta interesante destacar el nombre del menor, Yúnior como nombre que proviene de una escritura fonética de "Junior", el cual remite a una persona más joven que otra, generalmente su padre con quien comparte nombre por lo que se da la distinción. 
De esta forma, vemos cómo Rafa, a partir de una distinción de fenotipos, se empodera al tener rasgos blancos, por lo que "la insistencia de Rafa de la negrura de su hermano constituye una técnica de mantenimiento de poder en la relación fraternal [y] revela la internalización del racismo" (Figueroa 739).

Sin embargo, es en la figura de Ysrael donde el juego se aleja de toda comicidad y risa, así como la infancia de toda inocencia y pureza. En la medida que "el juego entra en un terreno complejo de perversión y crueldad [...] [siendo] una forma de ejercer poder [...] [y] de imponer cierta arbitraria voluntad sobre aquellos [...] a quienes se pueden humillar" (Jeftanovic 46). La tensión a lo largo de todo el cuento está en narrar los golpes, intimidaciones y burlas que tanto los protagonistas como los otros niños le hacían a Ysrael, un niño a quien se le desfiguró la cara al ser mordido por un cerdo, por lo que lleva una máscara: "Enséñanos la cara, le gritábamos. Déjanos verla solo una vez. ¡Le has dado cabrón! [...] Nos echamos a reír y volvimos a nuestros juegos de pelota “ (Díaz 22-3).

Los niños presentan una atracción por el misterioso y abominable rostro de Ysrael y es precisamente este morbo el que mueve el encuentro entre ellos. Rafa y Yúnior, tras fingir un motivo para dialogar, provocan la pelea que permitirá ver lo oculto y confirmar o no sus imaginaciones: "[quiero] hacerle una visita a ese muchacho [...] me han dicho que es espantoso [...] Seguro que los ojos fueron lo primero que buscó el cerdo [...] La mejillas decía. Y la barbilla. Pero la frente le tuvo que costar mucho más. La piel está tensa" $(11,16,17)$.

La curiosidad por ver su rostro, desatada por la morbosidad infantil, desencadena, por medio de una estrategia maquiavélica, un comportamiento agresivo y de coerción. No solo le tiran piedras sino que finalmente Rafa logra darle en la cabeza con una botella e incita a Yúnior a patearle las costillas, para así, bajo pleno sometimiento físico, verle su monstruosa cara:

La oreja izquierda era un muñón y a través de un orificio que tenía en la mejilla se veía la masa venosa de la lengua. Carecía de labios. Tenía la cabeza apepinada, los ojos se le habían vuelto blancuzcos y llevaba al descubierto los músculos del cuello. Cuando el cerdo entró en la casa él era un niño de pecho (Díaz 26).

El cuento de Junot Díaz, a partir de la presencia de niños que reproducen el discurso hegemónico (Rafa), junto a otros que representan la situación del subyugado (Yúnior) o del oprimido (Ysrael), cuestiona el imaginario nacional, sus íconos y discursos, funcionando como un contrarrelato de lo dominicano.

Sin embargo, es en el simbólico cuerpo de Ysrael donde la infancia es desmantelada y la identidad (¿dominicana?) pisoteada, invalidada. La pérdida del rostro en sus primeros meses de vida dio paso a un devenir monstruoso: el personaje, a partir de "un proceso de desubjetivación [debido a] la borradura de la cara y el encuentro con una carne [se] torna materia monstruosa en tanto que pura potencia de variación y principio de [des] composición" (Giorgi 328); y esta anomalía, que debe ocultarse, en lugar de generar un 
terror en los niños del cual hay que escapar, hace que aflore la crueldad infantil, la humillación psicológica y la violencia física.

Por lo tanto, el cuerpo enfermo de Ysrael, asumiendo una condición de desterritorializado, es visto como un cuerpo del que hay que burlarse y eliminar. Es un cuerpo concebido como un desecho en el que no se inscribe ni identidad ni derecho.

\section{Cocuyo de Severo Sarduy: del infante atormentado al exterminador de la humanidad}

Por su parte, Cocuyo, el protagonista de la novela de Sarduy, alejado de las indiferencias emocionales de los personajes de Díaz (particularmente de Rafa) e inserto dentro de una realidad familiar más estable o convencional, nos inserta en una aterradora y circular dinámica de aniquilación, esta vez ya no provocada ni por el juego ni por el morbo. Cocuyo, un niño masturbador compulsivo, cabezón y de ojos chinos, víctima de burlas y reproches, "es el niño marginal que pasa de sus familiares [... ] a los avatares de la adolescencia desprotegida en los márgenes sórdidos de una ciudad decadente" (Vilahomat).

La traumática humillación de ser visto por sus tías cayéndose del orinal ${ }^{4}$ y el horror que sintió no solo al ver cómo durante el ciclón una plancha de zinc degollaba a un negro, sino también la reprenda familiar recibida por quedarse afásico, incapaz de relatarles el siniestro, hacen que Cocuyo, a través de un ritual que se convertirá en iniciático, corrompa su atormentada infancia, dándole muerte a sus familiares:

La familia, como siempre sucede ante los adefesios indefensos, duplicó su crueldad. Las tías emprendieron una danza reprobatoria -porque un machito no puede ablandarse- [...] [y] el padre repetía ¡Válgame Dios, válgame Dios!” (26, énfasis del original), "[y fue entonces como Cocuyo] huyó a la cocina cabizbajo, ocultándose la cara, entre sollozos. [...] Contó a los miembros de la familia. Preparó tazas de tilo. Para todos, menos para él. Las espolvoreó generosamente con matarratas. Con sumo cuidado, las dispuso en una bandeja” (Sarduy 27).

El fuerte simbolismo y el intenso juego lingüístico de la obra están al servicio de componer una abyecta atmósfera de agobio y sufrimiento, donde las apreciaciones de los otros son las que guían este sádico actuar. Cocuyo se nos describe física y psicológicamente como un infante demacrado y atormentado: sus piernas son temblorosas, el cuerpo le suda, en ocasiones siente calambres en el vientre (134) o siente el pecho oprimido (137), y son varias las veces en las que la enunciación termina con "Cocuyo lloró". El sentimiento que atraviesa toda la novela es el miedo. No solo el narrador nos señala que es "algo que

4 En este punto cobra importancia, siguiendo una línea propia del psicoanálisis, la repetición como síntoma del trauma, en la medida en que tal acontecimiento reaparece compulsivamente en el pensamiento de Cocuyo a lo largo de la novela. 
de sobra él conocía" (81), sino que Cocuyo al terminar de suministrar el veneno, asume ser movido por este: "Para que nadie sepa que tengo miedo" $(27)^{5}$.

En la narración de Sarduy, se problematiza la figura de los adultos no solo en el argumento sino también a nivel retórico, en este sentido, destacan las atribuciones que se les suele dar a los mayores, estos son esperpentos, inquisidores, verdugos, corruptores, desvirgadores. Así como cada vez que en la narración se hace mención a las miradas sobre la figura de Cocuyo se alude a la sensación de ser acribillado, fijado, crucificado, fosilizado, reprobado.

“¿Qué pague su crimen, ese monstruo diabólico! ¡[que] quiso envenenar a los suyos con una pócima!" (50) fueron los gritos de los peritos al descubrir su acto, y son los que determinan la condición del protagonista: el niño deforme y frágil, sancionado por una supuesta conducta homosexual y hazmerreír de la familia, no es más que un criminal, un monstruo.

Sin embargo, huir de la casa y de la justicia no le trae calma ni risa, ni caricias ni mitigación de su miedo, al contrario, en este intento de emancipación familiar y de búsqueda de protección, se encuentra con una ciudad que está en ruinas, que es sórdida y endemoniada ${ }^{6}$ y que está llena de ratas dispuestas a esclavizar, a prostituir, a matar.

Por lo tanto, y tras este viaje psicológico y espacial, en el que se abandona la condición de niño bajo el amparo de un hogar-casa y se pasa a un estado de orfandad en las calles, Cocuyo finalmente decide contribuir en dar limpieza y orden a la sociedad, cerrando la novela con el retorno del ser diabólico:

el género humano le pareció [...] como una deyección irrecuperable, como un resto. Eso: el residuo, la ruina de un ser ideal tramado en los orígenes por algún dios iluso y a fin de cuentas reducido [...] a esta suciedad esencial (179) [...] Todos traicionaban. Todo asqueaba. Pero en el fondo -se dijo- les quedaba agradecido: le habían mostrado el verdadero rostro del hombre, su esencial doblez, su necesidad [...] de trampa, de mezquindad. Ahora los sabía capaces de todo: de vender padre y madre, de entregar a la Inquisición y a la quema el ser que simulan proteger. Capaces de felonía, de usura con los suyos. Capaces de mentir [...]. Se juró volver, para exterminarnos a todos. Y a él mismo, y así limpiar el universo de tanto estiércol. Sabía muy bien dónde comprar matarratas, y cómo mezclarlo sin que nadie se diera cuenta, con el ron (Sarduy 208-9, énfasis del original).

En la obra de Severo Sarduy, el discurso hegemónico, plasmado particularmente en lo relativo a la heteronormatividad, a ese patriarcado normativo, se inscribe en el núcleo familiar. La familia, en cuanto alegoría de la sociedad, funciona como fuerza que dificulta el proceso subjetivo del niño protagonista; por lo que en el relato se cuestiona la

5 Esta frase de Cocuyo, que cierra el primer capítulo, es también el título de este.

6 Son numerosos los episodios en los que el narrador califica a La Habana como una ciudad endemoniada, asimilándola al infierno. 
idea de la familia comprendida como ente fundante, y con ello se desmantela el mito del hogar como espacio de lo seguro, como refugio de lo intocable, y con ello, la idea de los padres como figuras contenedoras (Jeftanovic 15), siendo la casa, más bien un espacio de lo arbitrario y lo represor. Es decir, hay una desfamiliarización del relato del hogar, al relativizar la idea de la casa como un lugar de intimidad y protección.

El infante, concebido como un sujeto permeable, vigilado y por educar, problematiza las relaciones (de poder) con las figuras paternales oficiales y se resiste a ese disciplinamiento. Darle muerte a los parientes pasa a comprenderse como una "venganza contra la autoridad que lo ha herido, intentando alcanzar la libertad que añora[n] y pretendiendo independizarse a través de una maquinación fría y racional" (Pérez 123). El parricidio y el desenlace apocalíptico se configuran, entonces, como denuncias de las injusticias y abusos, las cuales se realizan a partir de un accionar que combina terror y rebeldía. El personaje pretende, a partir de un acto criminal, liberarse de esas ideologías que no le son propias, es decir, de la concepción de masculinidad que le han impuesto.

Cocuyo en su proceso cognitivo y subjetivo experimenta (en él y en los demás) la maldad humana y la comprende como algo intrínseco. Por lo que el monstruo, entendido como "algo que no solo irrumpe el estado de las cosas sino que además lo amenaza" (Cortés-Rocca 340), como anomalía y peligro, viene a ser el ser humano en sí mismo.

En este entorno, donde la familia se ha vuelto extraña, los vínculos parentales ajenos, y la infancia se ha desviado ${ }^{7}$, no hay más treta para este débil ${ }^{8}$ que la exterminación. En sus propias palabras: "des-existir". La idea de terminar con la vida de los demás comienza ya en el segundo capítulo, cuando Cocuyo huye y se sanciona a sí mismo deseando ser otro: "Sentía, en medio de la muchedumbre, la escoria de su cuerpo, la sensación de arrastrar una suciedad [...] quería des-existir. Ser otro" (53).

\section{Papi de Rita Indiana Hernández: la niñería en estado de delirio}

En Papi de Rita Indiana Hernández la infante se desenvuelve en una sociedad caribeña del consumo compulsivo y constituida a partir de la fusión de referentes locales con globales, propios de los mass media. Es decir, y siguiendo a Eloy Fernández, la autora, por medio de la ironía y la parodia, nos inserta en una estética narrativa de la implosión mediática, del afterpop?.

$7 \quad$ En este sentido, comprendo la desviación del infante no solo por su pulsión con respecto a la muerte sino también por su supuesta condición de homosexual en potencia, ya que la homosexualidad también se ha visto envuelta en la categoría de lo monstruoso.

8 Me remito a las ideas desarrolladas de Josefina Ludmer sobre los artificios que desarrolla el sujeto en situación de subordinación y marginalidad para ampliar su campo de acción. Véase Josefina Ludmer (1984), "Las tretas del débil".

9 Para Eloy Fernández esta narrativa es implosiva "en la medida en que reproduce y pone en práctica la implosión de los signos oficiada por los medios de comunicación [...] construyendo un paisaje mediático formado por un conjunto de iconos y representaciones [...] que constituyen la esfera del consumo y la información" (Fernández, 
La protagonista y narradora, una raquítica niña de ocho años, amante del skateboard, relata su relación con su padre, papi, un adinerado mafioso dominicano, macho seductor, que vive en los Estados Unidos y que ocasionalmente viaja a la isla. Un hombre que es buscado por todos: desean su dinero, sus negocios, su sexo ${ }^{10}$.

El eje articulador del relato y donde surge la tensión dramática es la figura de este papi todopoderoso, de pleno poder adquisitivo, "mesías del consumo" y representante de una "lumpenburguesía neocolonial” (Duchesne-Winter 301 y 303), en la medida en que, ante su ausencia, y siguiendo a Baudrillard, la niña se cobija en un vínculo filial-paternal que no es más que un delirante simulacro ${ }^{11}$ en el que él es idealizado e hiperbolizado a partir de sus bienes:

Papi tiene más de to que el tuyo [...] Mi papi tiene más carros que el tuyo, más carros que el diablo. Mi papi tiene tantos carros, tantos pianos, tantos botes, tantas metralletas, botas, chaquetas, chamarras, helipuertos, mi papi tiene tantas botas, mi papi tiene tantas novias, mi papi tiene tantas botas, de vaquero con águilas y serpientes dibujadas en la piel [...] Botas para jugar polo [...] botas de motocross [...] Porque papi tiene tanto dinero que tiene que usar una cartera de mujer [...] a veces papi prefiere comprar la tienda y quedarnos a dormir allí mismo, entre aires acondicionados, neveras, licuadoras, televisores y demás artículos para el hogar (Indiana Hernández 23, 35-6).

En este relatar las vivencias junto a papi -las cuales están todas condicionadas por la participación en el mercado ${ }^{12}$ y que a grandes rasgos se resumen en reuniones con sus grotescos socios, fugas disfrazadas de viajes a parques temáticos, y eternas esperas ${ }^{13}$ - la niña, bajo una descripción completamente carente de toda calificación valorativa peyorativa, lo que deja entrever su inocencia, nos presenta una ciudad gobernada por pobreza,

Afterpop 65-6). Por tanto, la actitud afterpop, se explica al tener una disposición de ánimo seriamente frívola que implica un doble movimiento: "por una parte una crítica a la cultura literaria oficial realizada con medios bajos; por otra parte, la reconsideración del espacio pop como un tema cómico -y no dramático" (Fernández, Afterpop 72).

10 Cabe profundizar en las diferentes lecturas de la novela, realizadas por De Maesenner y Duchesne-Winter en las que se relaciona la figura de papi con el Estado; así como en el análisis gramatical de la presencia de este papi siempre en minúsculas y en diminutivo, nunca padre ni papá.

11 Baudrillard señala que "disimular es fingir no tener lo que se tiene. [Mientras que] simular es fingir tener lo que no se tiene. Lo uno remite a la presencia, lo otro a la ausencia" (7), por lo que en este caso, la niña simula tener un padre.

12 El relato no solo está desbordado por objetos, marcas, películas, canciones, sino que también por los verbos tener y comprar. Lo importante son las posesiones de papi: las novias de papi, los socios de papi, los hijos de papi, las mercancías de papi.

13 En este punto destaca el inicio del capítulo 4 en el que la niña relata la tétrica espera a su padre quien iba a llevarla a la playa. El paso del tiempo es narrado por la niña a partir de la descomposición de la comida que la madre le lleva y de las heridas que el traje de baño, que ya le aprieta, le hacen en su cuerpo: "Me duermo con el traje de baño puesto porque papi me ha dicho que me va a llevar a la playa [...] Cuando estoy lista me siento en la mecedora [...] que por supuesto, me ha comprado papi. Allí estoy meciéndome, meciéndome [...] a las siete mami empieza a abrirme la boca con un gato hidráulico y ella y el haitiano de la construcción de enfrente que mami ha traído para que la ayude, me introducen un tubo transparente por donde me alimentan [...] Con la crecedera el traje de baño me aprieta tanto que la piel se ha amoratado [...] primero vienen las llagas, luego las pústulas. El traje de baño se confunde con mis heridas [...] traen un sacerdote para que me haga entrar en razón [...] Luego con la cabeza debajo de la almohada trato de imaginarme en qué parte de 'al doblar la esquina' está papi y cómo es esta esquina y cómo hay que hacer para doblarla" (54, 56 y 59$)$. 
crímenes, mafia, trata de blancas, contrabando, abortos ilegales, etc., los cuales solo son aludidos y nunca pronunciados ya que son conceptos que ella desconoce.

En la novela, y con una actitud estética perversa, en cuanto a su disposición a corromper y desviar una idea (Kristeva 25), la infancia es desacralizada, así como los referentes infantiles son torcidos, invertidos: papi, desde la primera línea, ya no es asimilado al príncipe azul de los cuentos de hadas sino que es equiparado a un monstruo: "Papi es como Jason, el de Viernes trece. O como Freddy Krueger” (Indiana Hernández 10); el caramelo ya no es un objeto de deleite sino un arma: "Dispara coño dispara', dice papi que se ha olvidado de pasarme un revólver y me saco el lollypop de la boca [y se lo] entierro en el ojo a la infierna" (31); y los personajes de los dibujos animados son vinculados a situaciones de violencia y muerte: "En la tele Charlie Brown participa en un spelling bee contest, a los que fallan las cabezas les explotan" (78); "el gordito está en el suelo y papi trata de despertarlo con una patada en la cabeza mientras limpia su pistola con una toallita de pato Donald que fue lo último que compramos" (109).

El delirio de la infante se termina por consolidar casi en el cierre de la novela, cuando, tras el asesinato de papi con tres disparos en la cabeza y el rechazo a creer que es su cuerpo, ella se convence de que es papi, dando así paso a un relato de tono profético: "Papi estaba en mí y yo en papi [...] Yo era igualita a papi. Yo era papi. Yo soy papi" (197).

Parodiando los espectáculos multitudinarios, como las ceremonias religiosas y los conciertos musicales, la niña consagra a su padre, esta omnipresencia fantasmal-espectroespectacular (Duchesne-Winter), como un culto:

Papi es como Jason. Aplausos, aleluyas, amén. Que cuando uno menos lo espera se aparece. Aplausos, aleluyas, amén. Pero en lo que más se parece papi a Jason... Aplausos, aleluyas, amén. Es en que vuelve siempre. Aunque lo maten. La gente se pone mala, gritan, chillan, tiemblan, hay unas muchachitas que se desmayan y las levantan para traerlas al escenario flotando sobre el mar de manos. Los de seguridad se ocupan. Papi tiene más de todo que el tuyo [...] Papi tiene más carros que el diablo. Aleluyas, aleluyas. Ovación (Indiana Hernández 209).

En la novela Papi, Rita Indiana Hernández construye un relato en el que los medios de comunicación y los objetos del mercado desplazan a las instituciones tradicionales hegemónicas y -como propio de la postmodernidad y las sociedades globalizadas neoliberales- se constituyen como nuevos dispositivos de poder y persuasión, así como nuevas religiones a las cuales rendirles culto.

Papi nos inserta en una monstruosa sociedad del espectáculo en la que tanto el espacio como los sujetos pasan a estar condicionados por la desenfrenada participación en el consumo, lo que genera nuevas prácticas sociales y nuevos referentes de identificación. El espectáculo, logrado por la total ocupación de la mercancía en la vida social, y por la mediación de las imágenes en las relaciones, pasa a ser la afirmación de la apariencia (Debord $4,10,37$ ) y es en ella donde la protagonista legitima su simulacro paterno. La niña que devora la imagen de su padre pasa a ser alienada por ese papi-fetiche. 
El ritmo asfixiante de la novela, logrado a partir de una insistente y reiterativa enumeración, permite no solo graficar el deseo y gozo de la niña, sino que construir un discurso infantil nihilista crudamente excesivo y corrosivamente transparente, el cual está al servicio de una monstruosa magnificación del padre. Y esta grotesca espectacularización de la figura paterna en la imaginación infantil viene a funcionar como un ejemplo de cómo, por medio de la alienación, el espectáculo permite la completa ocultación y represión de la miseria social (Debord 63 y 122).

Siguiendo la lectura de que los sujetos pasan a reconocerse en las mercancías, es el cubrecamas de la protagonista el objeto donde se plasma su enajenada infancia, coexistiendo la dulzura con la maldad: "en cada casa papi me ha comprado una habitación con su cama, su tocador, su mesita de noche y su lamparita a juego, todo en mimbre pintado de blanco y la colcha reversible que de un lado es de Rainbow Brite y del otro es de los Gremlins" (Indiana Hernández 37).

\section{Conclusión: caribeñas poéticas de la niñería}

Las tres obras analizadas delinean una sociedad caribeña de la crueldad y del espectáculo grotesco en la que la violencia es legitimada y la muerte desacralizada. Y son los propios niños protagonistas quienes dentro de la cotidianeidad doméstica y privada de sus brutales conductas de aniquilación van dialogando con lo monstruoso en la medida en que, y de acuerdo a Foucault, "lo que define al monstruo es el hecho de que su existencia misma y su forma, [...] es violación de la sociedad [y] también de las leyes de la naturaleza [...] [por lo que] el monstruo es lo que combina lo posible y lo prohibido" (61). Bajo una actitud infantil morbosa, traumática o nihilista, se nos presentan personajes cuyos comportamientos bordean la locura y la criminalidad, dejando así entrever sus infracciones y anomalías, y con ello van delineándose como monstruos morales.

Los protagonistas, en su afán y necesidad de responder a las normativas paternas, familiares, nacionales se ven envueltos en situaciones en las que afloran sus impulsos de muerte y de agresión. Estos infantes, violentos y asesinos a sangre fría, dan cuenta de cómo los lugares del monstruo no son ya las tinieblas, ni la animación de lo inorgánico o lo muerto, sino el propio cuerpo y su propia subjetividad (Pedraza 35 y 39), es decir, de cómo lo monstruoso se ha ido instalando en el lugar de lo divino, lo sagrado.

Las letras del Caribe contemporáneas, inscritas en propuestas estéticas del realismo sucio, del feísmo y lo abyecto, se resisten al discurso exotista de lo caribeño y formulan una crítica y/o denuncia social a partir de lo reprimido, marginal y de abajo. La representación de estas culturas, que han sido arrumbadas por la categoría de primitivo, negándoseles su propia historia y subordinándolas a un centro (Cabo 96), implica inscribir la resistencia desde un lugar desaventajado (Jeftanovic 30), en el que cobran protagonismo nuevas voces fronterizas: niños y niñas que se aproximan a la realidad caribeña desde una perspectiva infantil, en la que el desconocimiento, la ingenuidad y curiosidad permiten un actuar y un 
decir liberado de estereotipos, eufemismos y de la dicotomía bien/mal, así como miradas alejadas de toda sorpresa y escándalo.

La voz de estos protagonistas -que están movidos por la travesura, la rabia, la represión, la búsqueda de aceptación y la locura-, viene a funcionar como testimonio de un contexto sociopolítico fundado en la violencia y el espectáculo, como una ficcionalización de los horrores reales. Los niños, expuestos a dinámicas de agresión y muerte, víctimas de paternidades ausentes, castradoras e idealizadas, experimentan una precoz integración en el mundo adulto y una crítica socialización (Cabo 10), por lo que, mediante siniestros y perversos comportamientos, en los que reproducen la crueldad que ven y que sufren, buscan empoderarse y así desprenderse de su subalternidad.

Narrados bajo un discurso de fantasía y horror, inocente y grotesco a la vez, los relatos se resisten a la representación de la infancia como un espacio sagrado e inmaculado. Son textos postinfantiles que fracturan las ideas preconcebidas en torno a la niñez, con lo que desmantelan el mito de la infancia como etapa idílica, inocente, asexuada, dulce. Junot Díaz, Severo Sarduy y Rita Indiana Hernández, a partir de la voz alterna del niño, quien es configurado como un cuerpo social enfermo, dan paso a relatos aberrantes en los que la tensión está en la miseria humana, la decadencia; en la corruptibilidad de la sociedad, del sujeto y del cuerpo mismo. Por tanto, en estas propuestas narrativas, que presentan una estética perversa en cuanto al elemento que desacralizan (el niño) y subversiva en cuanto al posicionamiento crítico-paródico frente al discurso del cual surgen (Caribe-Calibán), el Caribe es un paraíso habitado por demonios, más bien, por pequeños ángeles retorcidos.

\section{Referencias}

Anderson, Benedict. Comunidades imaginadas: reflexiones sobre el origen y la difusión del nacionalismo. México: FCE, 1993. Medio impreso.

Baudrillard, Jean. Cultura y simulacro. Barcelona: Kairós, 1978. Medio impreso.

Benítez Rojo, Antonio. La isla que se repite. Madrid: Casiopea, 1998. Medio impreso.

Cortés-Rocca, Paola. "Etnología ficcional. Brujos, zombis y otros cuentos caribeños". Revista Iberoamericana LXXV 227 (2009). 333-347. Medio impreso.

Debord, Guy. La sociedad del espectáculo. Valencia: Pre-Textos, 2003. Medio impreso.

Díaz, Junot. "Ysrael”. Los boys. Barcelona: De bolsillo, 2009. 11-27. Medio impreso.

Duchesne-Winter, Juan. "Papi, la profecía. Espectáculo e interrupción en Rita Indiana Hernández”. Revista de crítica literaria latinoamericana 67 (2008). 289-308. Medio impreso.

Fernández Porta, Eloy. Afterpop. La literatura de la implosión mediática. España: Berenice, 2009. Medio impreso.

--- "Relatos postinfantiles. Figuras de la niñez en la narrativa breve postmoderna". El día del niño. La infancia como territorio para el miedo. Ed. Rubén Lardín. Madrid: Valdemar, 2003. 311-343. Medio impreso. 
Fernández Retamar, Roberto. Todo Caliban. Buenos Aires: Clacso, 2004. Medio impreso. Figueroa, Ramón A. “Fantasmas ultramarinos: la dominicanidad en Julia Álvarez y Junot Díaz”. Revista Iberoamericana LXXI 212 (2005). 731-744. Medio impreso.

Foucault, Michel. Los anormales. Buenos Aires: FCE, 2000. Medio impreso.

Giorgi, Gabriel., coord. "Introducción- Política del monstruo". Revista Iberoamericana. LXXV 227 (2009). 323-329. Medio impreso.

Indiana Hernández, Rita. Papi. Cáceres: Periférica, 2011. Medio impreso.

Jeftanovic, Andrea, María José Navia, María Belén Pérez y Lucía Sayagués. Hablan los hijos. Discursos y estéticas de la perspectiva infantil en la literatura contemporánea. Santiago de Chile: Cuarto Propio, 2011. Medio impreso.

Kristeva, Julia. Poderes de la perversión. México: Siglo XXI, 2006. Medio impreso.

Ludmer, Josefina. "Las tretas del débil". La sartén por el mango. Eds. Patricia González y Eliana Ortega. Puerto Rico: El huracán, 1984. <http://www.josefinaludmer.com/ Josefina_Ludmer/articulos.html $>$. Fecha de ingreso: junio de 2012. Sitio web.

Pedraza, Pilar. "Teratología y nueva carne”. La nueva carne. Una estética perversa del cuerpo. Ed. Antonio José Navarro. Madrid: Valdemar, 2002. 35-72. Medio impreso.

Sarduy, Severo. Cocuyo. Barcelona: Tusquets, 1990. Medio impreso.

Torres-Saillant, Silvio. "La nacionalidad ficticia”. Revista Cielo Naranja. <http://www. cielonaranja.com/torres_saillant.htm>. Fecha de ingreso: marzo de 2010. Sitio web. Vilahomat, José Ramón. "Sátira híbrida y sujeto menipeo: la literatura cubana y latinoamericana actual”. Espéculo. Revista de estudios literarios. Universidad Complutense de Madrid. <http://www.ucm.es/info/especulo/numero44/satirahi.html>. Fecha de ingreso: junio de 2012. Sitio web. 